\title{
FKBP11 protects intestinal epithelial cells against inflammation-induced apoptosis via the JNK-caspase pathway in Crohn's disease
}

\author{
XIAOTONG WANG ${ }^{1 *}$, XIAOPENG CUI $^{2 *}$, CHUANWU ZHU $^{1}$, MING $^{1}{ }^{1}$, JUAN ZHAO $^{3}$, \\ ZHONGYI SHEN $^{3}$, XIAOHANG SHAN ${ }^{3}$, LIANG WANG ${ }^{3}$, HAN WU $^{4}$, YANTING SHEN ${ }^{5}$, \\ YOU NI ${ }^{5}$, DONGMEI ZHANG ${ }^{5}$ and GUOXIONG $\mathrm{ZHOU}^{3}$
}

\author{
${ }^{1}$ Department of Hepatology and Gastroenterology, The Fifth's People's Hospital of Suzhou, Suzhou, Jiangsu 215000; \\ Departments of ${ }^{2}$ General Surgery and ${ }^{3}$ Gastroenterology, Affiliated Hospital of Nantong University, Nantong, \\ Jiangsu 226001; ${ }^{4}$ Nanjing Drum Tower Hospital Clinical College of Nanjing Medical University, Nanjing, \\ Jiangsu 210000; ${ }^{5}$ Clinical Medical Research Center, The Second Affiliated Hospital of Nantong University, \\ Nantong, Jiangsu 226001, P.R. China
}

Received September 29, 2017; Accepted July 31, 2018

DOI: $10.3892 / \mathrm{mmr} .2018 .9485$

\begin{abstract}
Endoplasmic reticulum (ER) stress in intestinal epithelial cells (IECs) has an important role in the pathogenesis of Crohn's disease (CD). FK506 binding protein 11 (FKBP11), a member of the peptidyl-prolyl cis-trans isomerase family, is involved in the unfolded protein response (UPR) and is closely associated with inflammation. Previous bioinformatics analysis revealed a potential association between FKBP11 and human CD. Thus, the present study aimed to investigate the potential significance of FKBP11 in IEC homeostasis and CD. In the present study, increased expression of FKBP11 was detected in the intestinal inflammatory tissues of patients with CD. Furthermore, the results of the present study revealed that overexpression of FKBP11 was accompanied by increased expression levels of the ER stress marker $78 \mathrm{kDa}$ glucose-regulated protein in the colon tissues of a 2, 4, 6-trinitrobenzenesulphonic acid-induced mouse colitis model. Using interferon- $\gamma(\mathrm{IFN}-\gamma) /$ tumor necrosis factor- $\alpha$ (TNF- $\alpha$ )-stimulated IECs as an ER stress and apoptosis cell model, the associated of FKBP11 with ER stress and apoptosis levels was confirmed in IECs. Overexpression of FKBP11 was revealed to significantly attenuate the elevated expression of pro-apoptotic proteins ( $\mathrm{Bcl} 2$ associated $\mathrm{X}$ apoptosis regulator, caspase-12 and active caspase-3),
\end{abstract}

Correspondence to: Professor Guoxiong Zhou, Department of Gastroenterology, Affiliated Hospital of Nantong University, 20 Xisi Road, Nantong, Jiangsu 226001, P.R. China

E-mail: patty1128@163.com

*Contributed equally

Key words: Crohn's disease, FK506 binding protein 11, endoplasmic reticulum stress, intestinal epithelial cell, apoptosis suppress the phosphorylation of c-Jun N-terminal kinase (JNK), and decrease apoptosis of IFN- $\gamma / \mathrm{TNF}-\alpha$ stimulated IECs. Knockdown of FKBP11 by transfection with small interfering RNA further validated the aforementioned results. In conclusion, these results suggest that the UPR protein FKBP11 may protect IECs against IFN- $\gamma /$ TNF- $\alpha$ induced apoptosis by inhibiting the ER stress-associated $\mathrm{JNK} /$ caspase apoptotic pathway in CD.

\section{Introduction}

Inflammatory bowel disease (IBD) refers to chronic inflammatory disorders of the digestive tract, primarily including Crohn's disease (CD) and ulcerative colitis (1). $\mathrm{CD}$ is characterized by patchy mucosal and sub-mucosal inflammation, the presence of granulomas in $20 \%$ of patients, and the formation of fissures, fistulae and strictures that occur throughout the gastrointestinal tract $(2,3)$. CD has been estimated to affect 322 per 100,000 individuals in Europe $(2,4)$, and the prevalence of CD in Asia has been steadily increasing (5). Despite being widely studied, CD has no cure and its etiology remains largely unknown (6). Numerous factors have been suggested to contribute to CD pathogenesis, such as genetic predisposition, immunological dysregulation and environmental factors (7). The intestinal barrier is considered to represent the frontline against adverse challenges, such as smoking, infection or a high sugar diet (7). The balance between cellular apoptosis and proliferation is important for maintaining the integrity of intestinal epithelial cells (IECs). Excessive epithelial apoptosis disrupts the barrier functions of the intestinal epithelium, allowing the invasion of bacteria into the sub-mucosa and subsequently activating host inflammatory responses $(7,8)$. Increased apoptosis of IECs resulting in epithelial barrier defects has recently been suggested to directly contribute to CD development (9). However, the molecular mechanisms underlying IEC apoptosis in $\mathrm{CD}$ remain unclear. 
In eukaryotic cells, the accumulation of unfolded and misfolded proteins in the endoplasmic reticulum (ER) lumen, known as ER stress, triggers the unfolded protein response (UPR), which aims to resolve the protein folding defect and restore ER homeostasis (10). Three classical ER sensor proteins, inositol-requiring kinase $1 \alpha(\operatorname{IRE} 1 \alpha)$, pancreatic ER eIF2 $\alpha$ kinase (PERK) and activating transcription factor $6 \alpha$ (ATF6 $\alpha$ ), are involved in three main UPR pathways (11). If ER stress is severe or chronic, or the UPR is compromised and unable to restore ER protein-folding homeostasis, numerous apoptotic signaling pathways are activated $(12,13)$. Several intestinal cell populations, including Paneth and goblet cells, require robust ER function for protein folding, maturation and secretion (6). Accumulating preclinical and clinical studies suggest that ER stress and the UPR have a significant impact on the pathogenesis of IBD $(9,14)$. For example, increased expression of ER stress markers has been observed in the ileal and colonic mucosa of patients with IBD (15). Furthermore, genetic deletion of X-box-binding protein 1 in IECs, an important transcription factor of ER stress, has been revealed to result in spontaneous enteritis in mice (14). In addition, genetic deletion of IRE1 $\alpha$ in IECs has been demonstrated to lead to spontaneous colitis and increased sensitivity to chemical reagent-induced colitis in mice (16). Furthermore, interleukin-10, an anti-inflammatory cytokine, maintains intestinal homeostasis by promoting correct protein folding under adverse conditions in goblet cells $(17,18)$.

FK506 binding protein (FKBP11) belongs to the FK506 binding protein family, which possess peptidyl-prolyl cis-trans isomerase (PPIase) activity and are notable for their capacity to bind immunosuppressive drugs, including FK506 and rapamycin (19). FKBP11 mRNA is abundant in numerous secretory tissues, including the pancreas, stomach and salivary glands (19). FKBP11 protein contains a cleavable N-terminal signal sequence followed by a putative PPIase domain with homology to FKBP12 (19). PPIases catalyze the slow cis-trans isomerization of peptidyl-prolyl bonds to facilitate the protein folding process, and FKBP11 has been suggested to be involved in ER stress and UPR $(19,20)$. Highly expressed FKBP11 is involved in the pathogenesis of numerous ER stress-associated inflammatory diseases, including type 2 diabetes (21), systemic lupus erythematosus (SLE) (22) and hepatitis (23). Furthermore, a progressively elevated expression of FKBP11 has been previously detected during the development of hepatocellular carcinoma (HCC), which suggests that FKBP11 may be a potential early marker for HCC (23). In ER stress induced hepatic steatosis in mice, FKBP11 is a downstream molecule of the classical UPR transducer IRE1 $\alpha$ that promotes viable protein folding (24). Notably, previous bioinformatics analysis investigating IBD suggested that the FKBPI1 gene might be exclusively highly expressed in human $C D$, thus suggesting that FKPB11 may be involved in the pathogenesis of CD (25). However, the exact expression pattern and biological role of FKBP11 in CD remains unclear.

In the present study, the protein expression of FKBP11 in human $\mathrm{CD}$ colon tissues and a 2, 4, 6-trinitrobenzenesulphonic acid (TNBS)-induced mice colitis model was investigated. Using interferon- $\gamma($ IFN- $\gamma$ )/tumor necrosis factor- $\alpha$ (TNF- $\alpha)$-treated IEC models, the effect of FKBP11 on IECs apoptosis and its potential association with the ER stress-associated c-Jun-N-terminal kinase (JNK)-caspase apoptotic pathway was investigated in inflammation-injured IECs.

\section{Materials and methods}

Human tissues. Following approval from the Ethics Committee of the Affiliated Hospital of Nantong University (Nantong, China), samples were selected between September 2013 and June 2015. Prior to sample collection, all patients provided written informed consent. Patients with $\mathrm{CD}$ had been diagnosed according to standard clinical manifestations, endoscopy examination and histological criteria (26). The inclusion criteria included focal inflammation, irregular crypts and granuloma (27). Inflamed intestinal biopsy samples were obtained from patients with $\mathrm{CD}(\mathrm{n}=20 ; 11$ males and 9 females; age, 24-45). Control intestinal biopsy samples were obtained from noninflamed areas of patients with $C D(n=20 ; 10$ males and 10 females; age, 28-44).

Animals and induction of colitis. All animal care and surgical procedures were performed based on the Guide for the Care and Use of Laboratory Animals produced by the National Research Council in 1996 (28), and supported by the Chinese National Committee to Use of Experimental Animals for Medical Purposes, Jiangsu Branch(Nantong, China). Following the approval from the Ethics Committee of the Affiliated Hospital of Nantong University (permit no. 2014-L087), female BALB/c mice (aged 8-10 weeks; weight, 18-20 g; n=60) were obtained from the Animal Center of Nantong University (Nantong, China), randomized into 2 groups and kept in the laboratory of Animal Center $\left(22-24^{\circ} \mathrm{C}\right.$; humidity, $40 \pm 5 \%$ and a $12 \mathrm{~h}$ light/dark cycle) with free access to food and water. Mice were fasted for $24 \mathrm{~h}$ prior to further experimentation.

The animal colitis model was established using TNBS (Sigma-Aldrich; Merck KGaA, Darmstadt, Germany). Based on a previously published method (29), mice were injected intraperitoneally with pentobarbital sodium to induce anesthesia $(0.3 \%$ solution; $75 \mathrm{mg} / \mathrm{kg})$. In the experimental group, mice were administered $0.1 \mathrm{ml}$ TNBS (2.5\% (weight/volume) TNBS solution in $50 \%$ ethanol). In the control group, mice were administered $0.1 \mathrm{ml}$ of $50 \%$ ethanol alone (ETOH group) (30). A $1 \mathrm{ml}$ syringe containing a $3.5 \mathrm{~F}$ catheter was used to administer either TNBS or ethanol via gentle insertion from the anus into the colon. The depth of the catheter was $\sim 4 \mathrm{~cm}$ from the anus. The solution was slowly delivered into the intestine, and mice were held vertically for $1 \mathrm{~min}$ to improve the success rate of the enema.

Evaluation of TNBS-induced colitis. To investigate the severity of colitis, changes in body weight, piloerection, fecal traits and bloody stools were recorded daily, and mice colon tissues were obtained for histology and protein analyses. The mice from the experimental and control group were sacrificed by cervical dislocation at $0,1,2,3,4$ and 5 days' time intervals ( $\mathrm{n}=5$ per time interval). The mice colonic tissues were removed quickly and washed gently in PBS. Following this, colonic tissues were fixed in $4 \%$ paraformaldehyde $\left(4^{\circ} \mathrm{C}\right.$ for $\left.48 \mathrm{~h}\right)$, embedded in paraffin, sectioned ( $4 \mu \mathrm{m}$ thickness) and stained with $5 \%$ hematoxylin (10 min at room temperature) and $0.5 \%$ eosin 
(5 min at room temperature). The pathological slices were observed under a light microscope at a magnification of x200. According to a well-established scoring system (31), the degree of inflammation on microscopic colon sections was graded from 0 to 4 ( 0 , no signs of inflammation; 1 , very low levels of inflammation; 2 , low levels of leukocytic infiltration; 3 , high levels of thickening of the colon wall, high vascular density and leukocytic infiltration; 4, transmural infiltration, high vascular density, loss of goblet cells and thickening of the colon wall).

Cell culture and stimulation. HT-29 cells (a human colon epithelial cell line) were purchased from the Cell Library, China Academy of Science (Shanghai, China). HT-29 cells were cultured in complete medium consisting of RPMI-1640 (Invitrogen; Thermo Fisher Scientific, Inc., Waltham, MA, USA), containing 10\% fetal bovine serum (FBS; Sigma-Aldrich; Merck KGaA, Darmstadt, Germany) with $100 \mathrm{U} / \mathrm{ml}$ penicillin and $100 \mu \mathrm{g} / \mathrm{ml}$ streptomycin at $37^{\circ} \mathrm{C}$ in a 95\% air and $5 \% \mathrm{CO}_{2}$ atmosphere. The medium was replaced with fresh medium every 2 days. The cells were passaged every 3-4 days. Prior to subsequent experiments, HT-29 cells were incubated with IFN- $\gamma(2.5 \mathrm{ng} / \mathrm{ml})$ and TNF- $\alpha(50 \mathrm{ng} / \mathrm{ml}$; Sigma-Aldrich; Merck KGaA) for $24 \mathrm{~h}$.

Western blot analysis. In order to perform western blot analysis, colon tissues were washed with PBS and then frozen at $-80^{\circ} \mathrm{C}$. The colon tissues were cut using scissors on ice to prepare lysates, and then homogenized in lysis buffer (1\% NP-40, $50 \mathrm{mmol} / \mathrm{l}$ Tris, $\mathrm{pH}=7.5,5 \mathrm{mmol} / \mathrm{l}$ EDTA, $1 \%$ sodium deoxycholate, $1 \%$ sodium dodecyl sulfate (SDS), $1 \%$ Triton X-100, $1 \mathrm{mmol} / 1 \mathrm{PMSF}, 1 \mu \mathrm{g} / \mathrm{ml}$ leupeptin and $10 \mu \mathrm{g} / \mathrm{ml}$ aprotinin) and then centrifuged at $4^{\circ} \mathrm{C}$ for $20 \mathrm{~min}$ at $48,000 \times \mathrm{g}$ to collect the supernatant. Cell cultures were lysed with sodium lauryl sulfate loading buffer and then stored at $-80^{\circ} \mathrm{C}$ until further use. Following this, the protein concentration within the samples was determined using a Bradford assay (Bio-Rad Laboratories, Inc., Hercules, CA, USA). Proteins from cell lysates ( $30 \mu \mathrm{g} / \mathrm{lane})$ were separated by $10 \%$ SDS-PAGE analysis and then transferred to polyvinylidene difluoride membranes (EMD Millipore, Billerica, MA, USA). The membranes were blocked with $5 \%$ non-fat milk for $1 \mathrm{~h}$ at room temperature and incubated overnight at $4^{\circ} \mathrm{C}$ with the following primary antibodies: FK506 binding protein 11 (FKBP11, goat; 1:500; cat. no. AP6790a; Abgent, Inc., San Diego, CA, USA), 78 kDa glucose-regulated protein (GRP78, mouse; 1:500; cat. no. sc-13539), Bcl2 associated X apoptosis regulator (Bax, rabbit; 1:500; cat. no. sc-20067), proliferating cell nuclear antigen (PCNA, mouse; 1:500; cat. no. sc-25280; all Santa Cruz Biotechnology, Inc., Dallas, TX, USA), active caspase-3 (rabbit; 1:500; cat. no. AP3725a; Abgent, Inc.), c-Jun N-terminal kinase (JNK, mouse; 1:500; cat. no. sc-7345), phosphorylated JNK (p-JNK, mouse; 1:500), caspase-4 (human; 1:500; cat. no. sc-56056), caspase-12 (human; 1:500; sc56056), and glyceraldehyde-3-phosphate dehydrogenase (GAPDH, rabbit; 1:1,000; cat. no. sc-32233; all Santa Cruz Biotechnology, Inc.). Finally, the membranes were incubated with horseradish peroxidase-conjugated anti-goat, anti-mouse, anti-rabbit (1:5,000; cat. nos. sc-2347, sc-516102, sc-2357; Santa Cruz Biotechnology, Inc.) and anti-human
(1:5,000; cat. no. ab200699; Abcam, Cambridge, MA, USA) secondary antibodies for $2 \mathrm{~h}$ at room temperature and visualized using an enhanced chemiluminescence system (Pierce; Thermo Fisher Scientific, Inc., Waltham, MA, USA).

Immunohistochemistry studies. Mice colon tissues were fixed in $10 \%$ formalin $\left(4^{\circ} \mathrm{C}\right.$ for $\left.24 \mathrm{~h}\right)$ and then incubated with $20 \%$ sucrose $\left(4^{\circ} \mathrm{C}, 2-3\right.$ days), followed by $30 \%$ sucrose $\left(4^{\circ} \mathrm{C}\right.$, 2-3 days). The samples were embedded in optimal cutting temperature compound (Taihe Huamei Pharmaceutical Technology Co., Ltd., Shanghai, China) and then cut into $4 \mu \mathrm{m}$ sections using a cryostat. Specimens from patients with $\mathrm{CD}$ were fixed in formalin $\left(4^{\circ} \mathrm{C}\right.$ for $\left.24 \mathrm{~h}\right)$, dehydrated, embedded in paraffin and cut into $5 \mu \mathrm{m}$ sections, deparaffinized and rehydrated via descending alcohol series. All sections were processed in $10 \mathrm{mM}$ citrate buffer $(\mathrm{pH} \mathrm{6.0)}$ and heated to $121^{\circ} \mathrm{C}$ in an autoclave for $20 \mathrm{~min}$ to retrieve the antigen. Following this, the sections were soaked in $3 \%$ hydrogen peroxide to block the endogenous peroxidase activity for $40 \mathrm{~min}$ at room temperature. Following rinsing with PBS $(\mathrm{pH}=7.2)$, the sections were incubated with antibodies against FKBP11 (goat; 1:500; cat. no. AP6790a; Abgent, Inc.), GRP78 (mouse, 1:500; cat. no. sc-13539; Santa Cruz Biotechnology, Inc.) for $2 \mathrm{~h}$ at room temperature. All slides were processed using the peroxidase-anti-peroxidase method for secondary antibodies (anti-goat and anti-mouse; both 1:5,000; cat. nos. sc-2347 and sc-516102; Santa Cruz Biotechnology, Inc.) at room temperature for $30 \mathrm{~min}$ (Dako; Agilent Technologies, Inc., Santa Clara, CA, USA). Following rinsing with PBS, sections were incubated with diaminobenzidine mixture (0.1\% PBS, $0.02 \%$ diaminobenzidine tetrahydrochloride and $3 \% \mathrm{H}_{2} \mathrm{O}_{2}$ ) for $5 \mathrm{~min}$ at room temperature to investigate the peroxidase reaction. Following rinsing with water, sections were counterstained with hematoxylin and subsequently dehydrated. Images were captured using a light microscope at a magnification of $x 50$ and analyzed using Image-Pro Plus 7.0 (Media Cybernetics, Inc., Rockville, MD, USA) with the Olympus microscope (BX53; Olympus Corporation, Tokyo, Japan).

Cell apoptosis. A flow cytometry assay was performed to investigate the cell apoptosis and necrosis rates using an ApoScreen Annexin V kit (Southern Biotech, Birmingham, AL, USA), according to the manufacturer's protocol. Briefly, HT-29 cells were digested using $0.1 \%$ trypsin and then resuspended in cold binding buffer (10 mM HEPES, pH 7.4, $140 \mathrm{mM} \mathrm{NaCl}$, $2.5 \mathrm{mM} \mathrm{CaCl}_{2}$ and $0.1 \% \mathrm{BSA}$ ) at concentrations between $10^{5}$ and $10^{6} \mathrm{cells} / \mathrm{ml}$. Following this, labeled Annexin V $(10 \mu \mathrm{l})$ was added to $100 \mu \mathrm{l}$ of the cell suspension. Propidium iodide (PI) solution $(10 \mu \mathrm{l})$ and binding buffer $(380 \mu \mathrm{l})$ were then added to the cell suspension following incubation for $15 \mathrm{~min}$ on ice. Subsequently, the number of stained cells was investigated using a BD FACSAriaII flow cytometer (CXP software, version 2.2; FC500 flow cytometer; Beckman Coulter, Inc., Brea, CA, USA) (32).

FKBP11 and FKBP11 small interfering RNA (siRNA) transfection.FKBP11siRNA and control siRNA were obtained from Biomics Biopharma Limited (Nantong, China). The sequences of FKBP11siRNA used were as follows: siRNA\#1: 

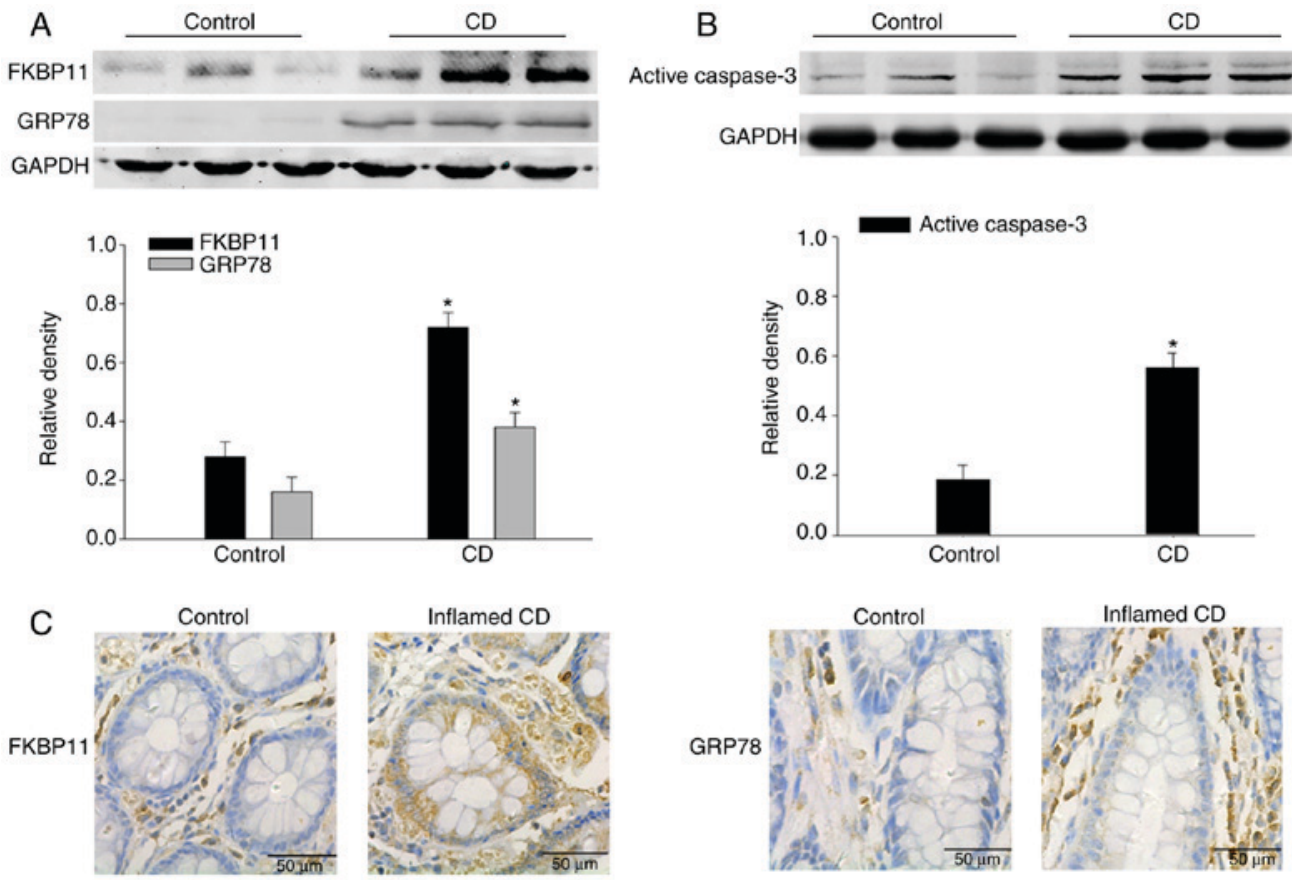

Figure 1. Expression of FKBP11 and GRP78 are increased in intestinal tissues of patients with CD. Western blot analyses of (A) FKBP11 and GRP78 expressions levels, and (B) active caspase-3 expression levels in the intestinal tissues of patients with active CD and control tissues. GAPDH was used as a loading control. Bar graphs demonstrate the semi-quantitative analysis of FKBP11, GRP78 and active caspase-3 protein expression levels vs. GAPDH. (C) Immunohistochemistry analysis of FKBP11 and GRP78 expressions in mucosal biopsies tissues obtained from inflamed tissues with active CD and control tissues. Scale bar, $50 \mu \mathrm{m}$. Data are presented as mean \pm standard error $(\mathrm{n}=3)$. ${ }^{*} \mathrm{P}<0.05$ vs. control. CD, Crohn's Disease; FKBP11, FK506 binding protein 11; GRP78, 78 kDa glucose-regulated protein.

5'-CACUAAUCCGAGCCAACUA-3', siRNA\#2: 5'-UGGAGC UGAUUGCACUAAU-3', siRNA\#3: 5'-UGGUAGAUGGAC GUAUUAU-3' and siRNA\#4: 5'-GAGCCAACUACUGGC UAAA-3'. The control siRNA sequence was 5'-UUCUCCGAA CGUGUCACGU-3'. The pCMV-HA-FKBP11 plasmid with hemagglutinin (HA) tag and control plasmid (pCMV-HA) were obtained from the Plasmid Library of Jikai (Shanghai GeneChem Co., Ltd., Shanghai, China). HT-29 cells were seeded 1 day prior to transfection using RPMI-1640 medium containing 10\% FBS. Transient transfection was performed using Lipofectamine 2000 (Thermo Fisher Scientific, Inc.), according to the manufacturer's instructions (33), $2 \mathrm{ml}$ Lipofectamine 2000 and $1 \mu \mathrm{g}$ FKBP11 plasmid were added individually into the $1.5 \mathrm{ml}$ tubes and mixed with OPTI-MEM medium for $20 \mathrm{~min}$. Then cells were incubated for $6 \mathrm{~h}$ at $37^{\circ} \mathrm{C}$ in RPMI-1640 medium in the absence of serum and antibiotics. Following this, the transfection mixtures were replaced with 10\% FBS containing RPMI-1640 medium, and cells were cultured for a further $48 \mathrm{~h}$ prior to further experimentation.

Statistical analysis. SPSS software (version 19.0; IBM Corp., Armonk, NY, USA) was used for data analysis. Data are expressed as the mean \pm standard error of the mean. Statistical analyses between two groups were performed using the Student's t test, and statistical analyses between multiple groups were performed using one-way analysis of variance. One-way analysis of variance followed by Dunnett's post hoc test was performed for multiple comparisons. Each experiment consisted of a minimum of three replicates per condition. $\mathrm{P}<0.05$ was considered to indicate a statistically significant result.

\section{Results}

FKBP11 and GRP78 expression levels are increased in the inflamed intestinal mucosal tissues of patients with $C D$. To investigate the potential contribution of FKBP11 in CD, western blot analysis was performed to determine the expression levels of FKBP11 in the colon biopsies from patients with CD. As shown in Fig. 1A, FKBP11 and GRP78 protein expression levels were significantly increased in the inflamed colon tissues of patients with active CD compared with the control. In addition, the protein expression level of active caspase-3 was significantly increased in the inflamed colon tissues of patients with active $\mathrm{CD}$ compared with the control (Fig. 1B). Immunohistochemistry analysis further verified the upregulated expression of FKBP11 and GRP78 in the inflamed intestinal mucosal tissues of patients with $\mathrm{CD}$ compared with the control (Fig. 1C and D). These results suggested that FKBP11 may be involved in the process of human CD.

TNBS-induced experimental colitis in mice. A TNBS induced mice colitis model was established to further investigate the role of FKBP11 in CD. This is a well-established model of colonic inflammation, resembling numerous primary clinical and morphological features of human CD (34). Compared with the ETOH control group, the body weight of the TNBS group began to decrease by day 1 of the model and reached a minimum body weight at day 3 (Fig. 2A). The histological scores reflecting inflammation levels of mice were significantly increased in the TNBS group compared with the control group, and reached a maximum score on day 3 (Fig. 2B). $\mathrm{H} \& \mathrm{E}$ staining revealed some $\mathrm{CD}$-like pathological changes in 

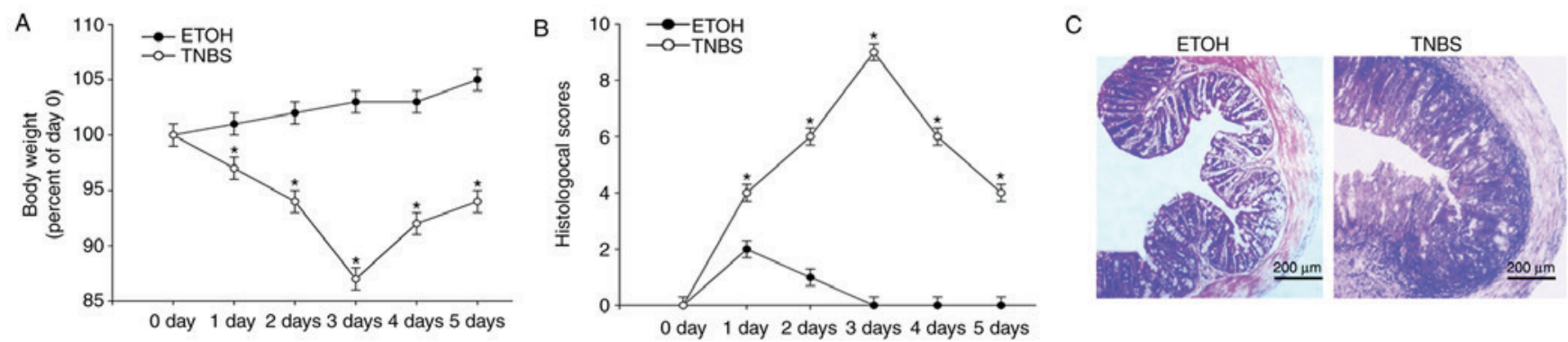

Figure 2. Indicators confirm success of the TNBS-induced colitis model. (A) Mice body weight changes following administration of TNBS or ETOH at 0, 1, 2, 3, 4 and 5 days time intervals post-treatment. (B) Histological scoring of the $\mathrm{H} \& \mathrm{E}$ staining results at $0,1,2,3,4$ and 5 days time intervals post-treatment with either TNBS or ETOH. (C) Representative light microscopy images of H\&E stained colonic tissues from mice following administration of TNBS or ETOH (scale bar, $200 \mu \mathrm{m}$ ). Arrows indicate areas of inflammatory cell infiltration and epithelial cell depletion. Data are presented as mean \pm standard error $(\mathrm{n}=3)$. "P<0.05 vs. ETOH. H\&E, hematoxylin and eosin; ETOH, ethanol; TNBS, 2, 4, 6-trinitrobenzenesulphonic acid.

A
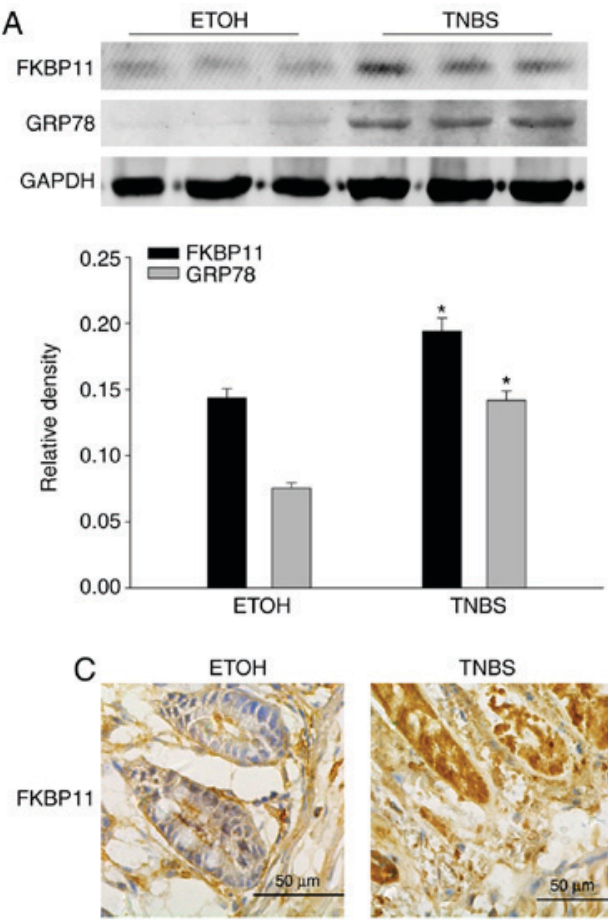

TNBS

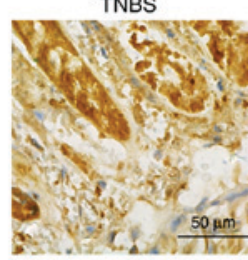

B
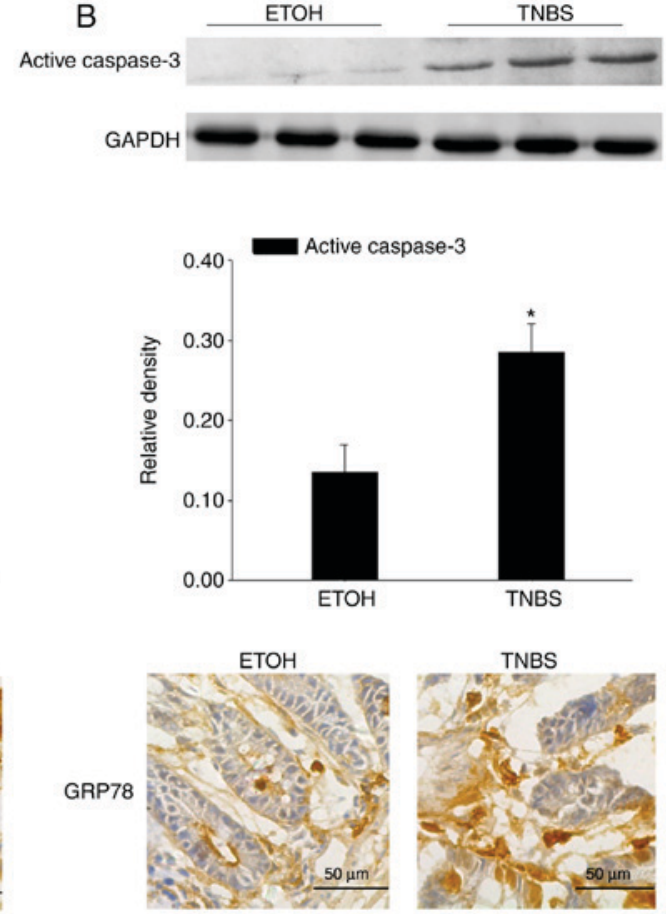

Figure 3. FKBP11 and GRP78 expression levels are increased in TNBS-induced colitis. Western blot analyses revealed that the expression levels of (A) FKBP11 and GRP78, and (B) active caspase-3 in TNBS induced colitis are significantly enhanced 3 days post-treatment compared with the ETOH group. Bar graphs demonstrate the quantitative analysis of FKBP11, GRP78 and active caspase-3 vs. GAPDH. (C) Immunohistochemistry analysis of FKBP11 and GRP78 expression in colonic mucosa of mice treated with TNBS for 3 days (scale bar, $50 \mu \mathrm{m}$ ). Data are presented as mean \pm standard error ( $\mathrm{n}=3$ ). $\mathrm{P}<0.05 \mathrm{vs}$. ETOH. ETOH, ethanol; TNBS, 2, 4, 6-trinitrobenzenesulphonic acid; FKBP11, FK506 binding protein 11; GRP78, 78 kDa glucose-regulated protein.

TNBS-treated colons, including inflammatory cell infiltration within the lamina propria, formation of ulceration, depletion of epithelial cells, edema and thickened colon wall (Fig. 2C), which was consistent with previous studies $(31,35)$. These results suggest that the TNBS-induced colitis model was well established in the present study. Furthermore, the results of the present study demonstrated that 3 days post-treatment with TNBS was the optimum time interval of acute inflammation, and therefore this tissue was retained for use in subsequent experiments.

Expression levels of FKBP11 and GRP78 are increased in TNBS-induced colitis in mice. Western blot analysis demonstrated that FKBP11, GRP78 and active caspase-3 protein expression levels were significantly increased in the mice colon tissues of the TNBS group compared with the ETOH group (Fig. 3A and B), which was consistent with the results obtained from the biopsies of patients with CD. Furthermore, immunohistochemistry analysis was performed to investigate the expression levels and distributions of FKBP11 and GRP78 proteins in the TNBS group. The TNBS group revealed markedly increased levels of FKBP11 and GRP78 expression, predominantly in the cytoplasm of IECs, compared with the ETOH group (Fig. 3C).

FKBPI1 regulates ER stress in IFN- $\gamma / T N F-\alpha$ treated IECs. Previous studies have revealed that ER stress is involved in the pathogenesis and progression of IBD (36,37). The expression levels of ER stress markers, such as GRP78 and DNA damage-inducible transcript 3 protein $(\mathrm{CHOP})$, have 

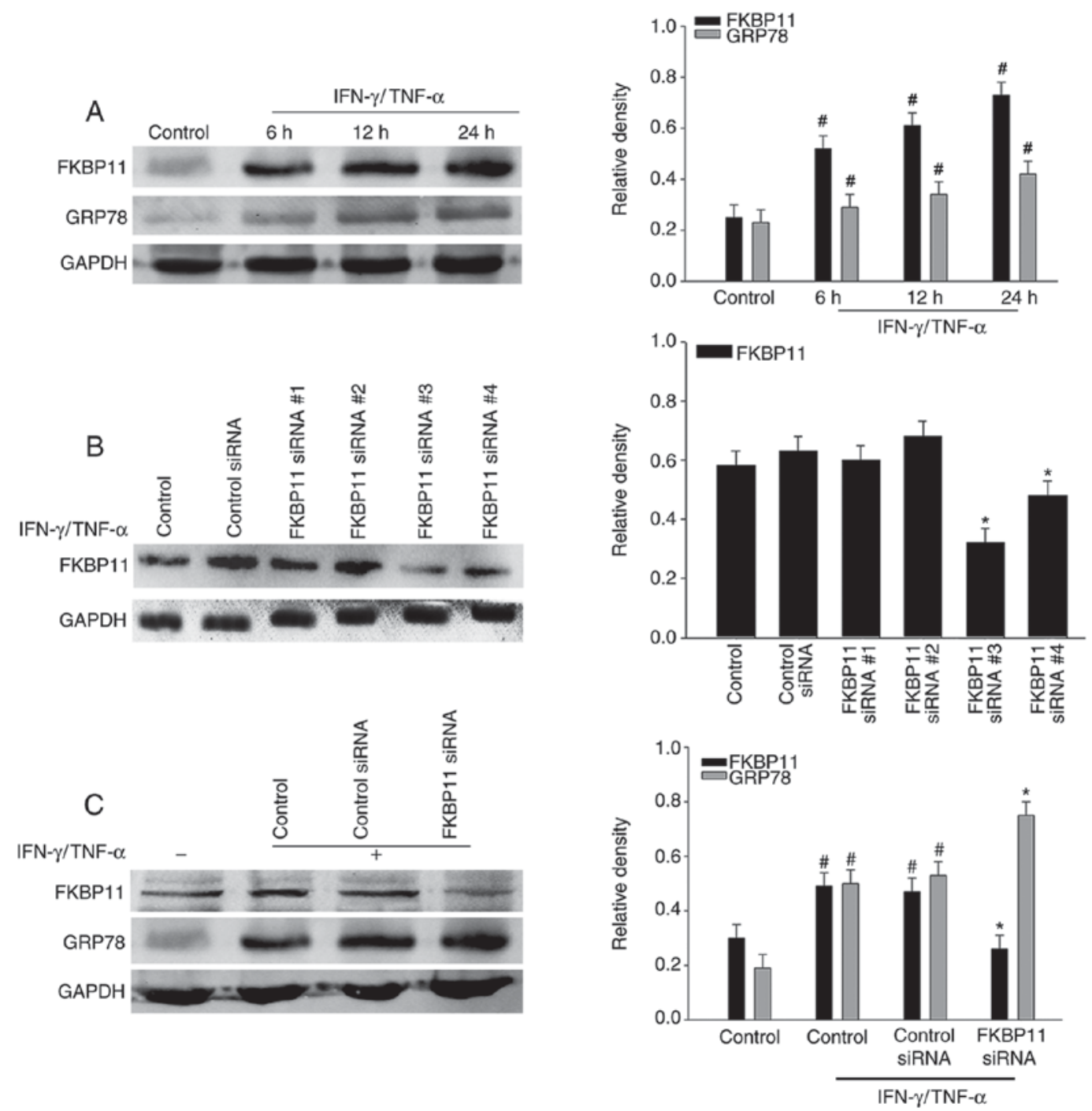

Figure 4. Association of FKBP11 expression levels with ER stress in IFN- $\gamma /$ TNF- $\alpha$-treated HT-29 cells. (A) HT-29 cells were treated with IFN- $\gamma(2.5 \mathrm{ng} / \mathrm{ml})$ and TNF- $\alpha(50 \mathrm{ng} / \mathrm{ml})$ for different time intervals $(0,6,12$ and $24 \mathrm{~h})$ to construct a cell model of ER stress. Western blot analyses revealed a significant upregulation of FKBP11 and GRP78 protein levels in IFN- $\gamma /$ TNF- $\alpha$-treated cells in a time-dependent manner. (B) FKBP11 expression following transfection with FKBP11 siRNA in HT-29 cells was revealed by western blot analyses, and transfection with FKBP11siRNA\#3 was revealed to exhibit the most significant downregulation of FKBP11 expression. (C) HT-29 cells were transfected with control siRNA or FKBP11siRNA for $48 \mathrm{~h}$, and then treated with IFN- $\gamma /$ TNF- $\alpha$ for $24 \mathrm{~h}$. Western blot analyses revealed that FKBP11 and GRP78 expression levels increased following IFN- $\gamma /$ TNF- $\alpha$ treated cells compared with the untreated control, and GRP78 expression was significantly increased following transfection of FKBP11siRNA compared with control siRNA. Bar graphs reveal the densities of FKBP11 or GRP78 protein levels vs. GAPDH. Data are presented as mean \pm standard error ( $\mathrm{n}=3$ ). ${ }^{*} \mathrm{P}<0.05$ vs. control siRNA; ${ }^{\#} \mathrm{P}<0.05$ vs. IFN- $\gamma /$ TNF- $\alpha$ untreated control. IFN- $\gamma$, interferon- $\gamma$; TNF- $\alpha$, tumor necrosis factor- $\alpha$; FKBP11, FK506 binding protein 11; GRP78, 78 kDa glucose-regulated protein; siRNA, small interfering RNA.

been previously demonstrated to be upregulated in inflamed intestines of IBD (38). To investigate the association between FKBP11 and ER stress in CD, HT-29 cells were treated with IFN- $\gamma(2.5 \mathrm{ng} / \mathrm{ml})$ and TNF- $\alpha(50 \mathrm{ng} / \mathrm{ml})$. FKBP11 protein levels significantly increased in a time-dependent manner following IFN- $\gamma / \mathrm{TNF}-\alpha$ stimulation compared with the control, which suggests that an IFN- $\gamma /$ TNF- $\alpha$ induced ER stress cell model had been successfully established (Fig. 4A). Following this, cells were transfected with control siRNA and FKBP11siRNAs, and the expression of FKBP11 was subsequently determined. Western blot analysis revealed that FKBP11-siRNA\#3 demonstrated the most efficient knockdown of FKBP11 expression (Fig. 4B), and therefore was subsequently chosen for use in further experiments. To investigate the association between FKBP11 and ER stress, the protein expression of FKBP11 was knocked down via RNA interference. Compared with the control siRNA group, suppression of FKBP11 expression with siRNA significantly enhanced the expression of GRP78 in IFN- $\gamma /$ TNF- $\alpha$-induced HT-29 cells (Fig. 4C). These results suggest that FKBP11 may regulate IFN- $\gamma /$ TNF- $\alpha$-induced ER stress in HT-29 cells.

FKBP11 protects $H T-29$ cells against IFN- $\gamma / T N F-\alpha$-induced apoptosis. It has been previously reported that increased apoptosis of IECs disrupts the integrity of the epithelial barrier and contributes to CD development (8). In the present study, it was demonstrated that combined IFN- $\gamma /$ TNF- $\alpha$ stimulation significantly enhanced the expression levels of pro-apoptotic proteins BAX and active caspase- 3 compared with the control, which suggests that an inflammation-triggered IEC apoptosis model 
A
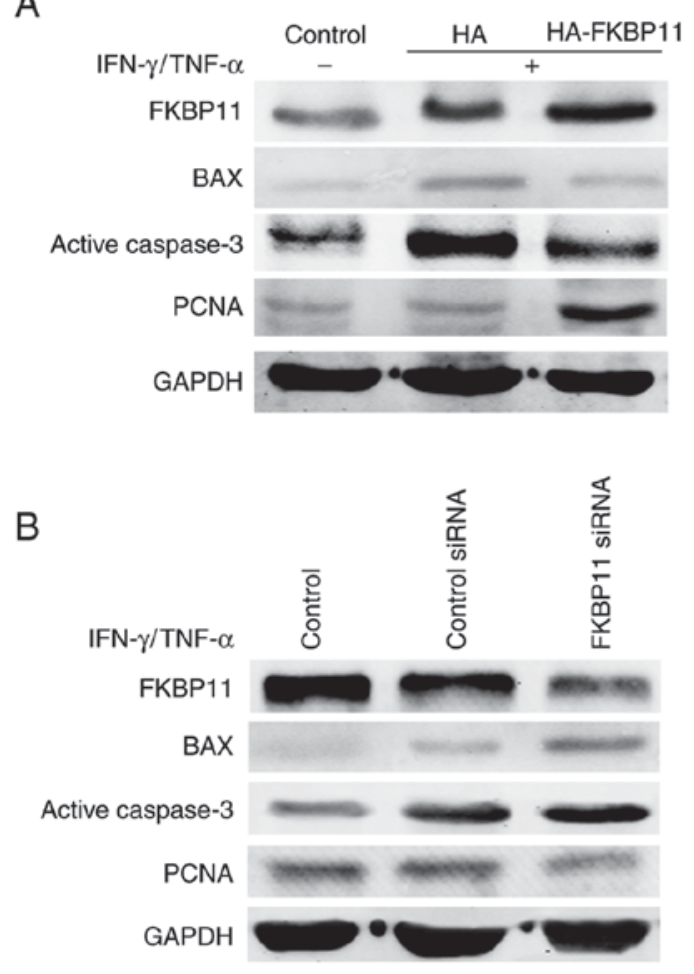
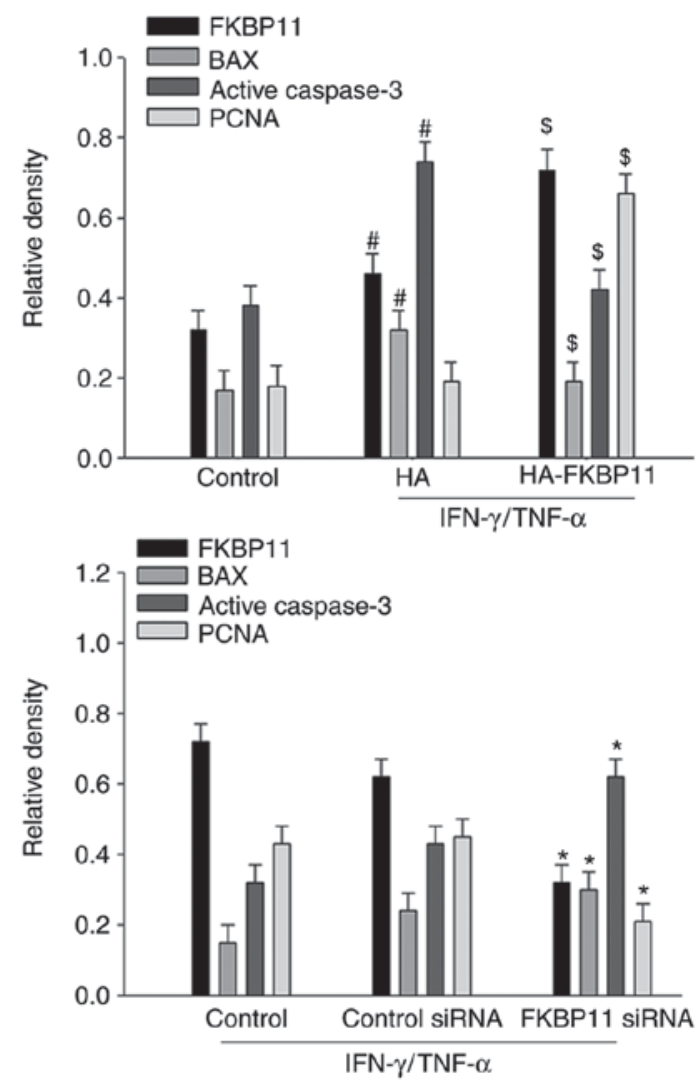

Figure 5. FKBP11 is involved in IFN- $\gamma /$ TNF- $\alpha$-induced apoptosis in HT-29 cells. (A) HT-29 cells were transfected with either the FKBP11 overexpressing plasmid pCMV-HA-FKBP11, blank control plasmid pCMV-HA, controls siRNA or FKBP11siRNA for $48 \mathrm{~h}$ and then treated with IFN- $\gamma(2.5 \mathrm{ng} / \mathrm{ml})$ and TNF- $\alpha$ $(50 \mathrm{ng} / \mathrm{ml})$ for $24 \mathrm{~h}$. Western blot analyses detected FKBP11, BAX and active caspase-3 expression levels following treatment with IFN- $\gamma /$ TNF- $\alpha$ compared with the untreated control and control plasmid (HA). ${ }^{*} \mathrm{P}<0.05$ vs. IFN- $\gamma / \mathrm{TNF}-\alpha$ untreated control; ${ }^{\$} \mathrm{P}<0.05$ vs. control plasmid pCMV-HA. (B) Western blot analyses detected FKBP11, BAX, active caspase-3 and PCNA following transfection with FKBP11 siRNA and treatment with IFN- $\gamma$ (2.5 ng/ml) and TNF- $\alpha$ $(50 \mathrm{ng} / \mathrm{ml})$ for $24 \mathrm{~h}$. Data are presented as mean \pm standard error $(\mathrm{n}=3)$. ${ }^{*} \mathrm{P}<0.05$ vs. control siRNA. HA, hemagglutinin; FKBP11, FK506 binding protein 11 ; siRNA, small interfering RNA; GRP78, 78 kDa glucose-regulated protein; IFN- $\gamma$, interferon- $\gamma$; TNF- $\alpha$, tumor necrosis factor- $\alpha$; BAX, Bcl2 associated X apoptosis regulator; PCNA, proliferating cell nuclear antigen.

had been successfully established (Fig. 5A). To investigate the function of FKBP11 in IFN- $\gamma /$ TNF- $\alpha$-induced IEC apoptosis, the pCMV-HA-FKBP11 plasmid was transfected into HT-29 cells to overexpress FKBP11 and the cells were then treated with IFN- $\gamma / \mathrm{TNF}-\alpha$. The results of the western blot analyses suggested that the expression of the pro-apoptotic markers BAX and active caspase-3 were significantly decreased when FKBP11 was overexpressed compared with the empty control plasmid group (Fig. 5A). In addition, in cell treated with IFN- $\gamma /$ TNF- $\alpha$, knockdown of FKBP11 using siRNA significantly increased the expression levels of BAX and active caspase-3 compared with the control siRNA group (Fig. 5B). These results suggested that FKBP11 may have an important role in IFN- $\gamma /$ TNF- $\alpha$ stimulated IEC apoptosis.

FKBP11 suppresses IFN- $\gamma / T N F-\alpha$-induced IEC apoptosis by inhibiting the JNK-caspase signaling pathway. To further investigate the importance of FKBP11 in apoptosis, the effect of FKBP11 overexpression in IECs following IFN- $\gamma /$ TNF- $\alpha$-induced cellular apoptosis was investigated using an Annexin V/PI staining assay. As shown in Fig. 6A, following IFN- $\gamma /$ TNF- $\alpha$ administration, the Annexin $\mathrm{V}^{+} / \mathrm{PI}^{+}$ double positive cell ratio was notably increased compared with the control, suggesting that a cellular apoptosis model had been successfully established. Furthermore, FKBP11 overexpression markedly attenuated the IFN- $\gamma /$ TNF- $\alpha$ induced apoptosis of cells compared with the control plasmid group (Fig. 6A). A previous study demonstrated that excessive or prolonged ER stress leads to the induction of apoptotic processes via CHOP, JNK and/or caspase dependent pathways (39). Human caspase-12 has no role in apoptotic pathways (40) and it is still controversial that human caspase-12 acts as a functional counterpart of mouse caspase-12. Of note, the amino acid sequence of mouse caspase-12 has a $61 \%$ identity with human caspase-4, which is involved in apoptosis induced by ER stress (41). Therefore, the phosphorylation levels of JNK and expression levels of caspase-4 in IECs subjected to IFN- $\gamma$ and TNF- $\alpha$ administration were investigated. As shown in Fig. 6B, HT-29 cells exhibited significantly increased levels of phosphorylated (p)-JNK following IFN- $\gamma /$ TNF- $\alpha$ administration compared with the control, thus suggesting activation of the JNK signaling pathway. Overexpression of FKBP11 significantly suppressed the levels of phospho-JNK in IFN- $\gamma /$ TNF- $\alpha$-treated cells compared with control cells treated with IFN- $\gamma /$ TNF- $\alpha$ (Fig. 6B). In addition, cells treated with IFN- $\gamma /$ TNF- $\alpha$ and overexpressing FKBP11 significantly suppressed caspase-4 expression compared with control cells treated with IFN- $\gamma / \mathrm{TNF}-\alpha$. In conclusion, these results suggest that FKBP11 may protect IECs against 

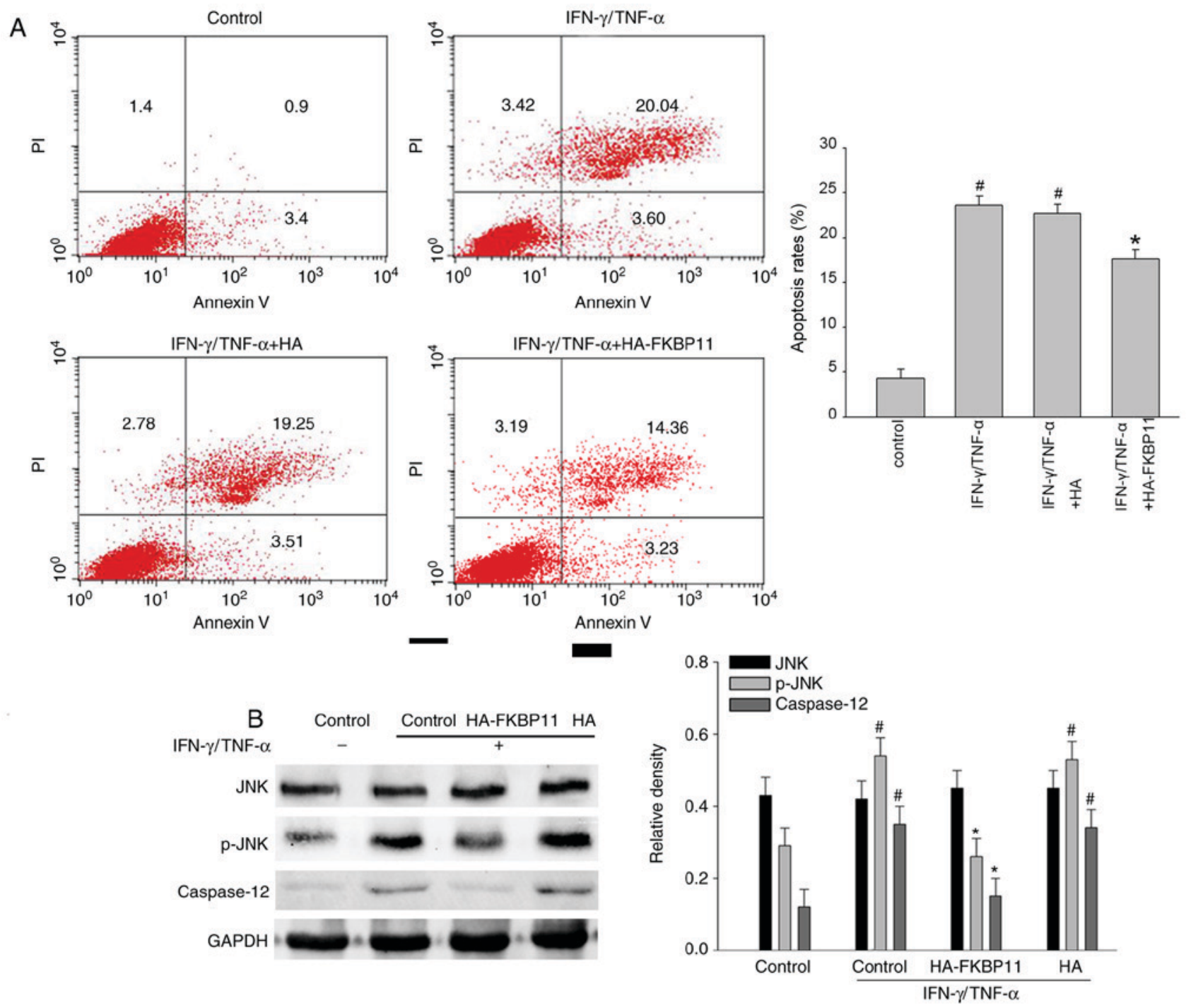

Figure 6. FKBP11 protects HT-29 cells against IFN- $\gamma /$ TNF- $\alpha$ induced apoptosis by inhibiting the JNK/caspase signaling pathway. (A) Cellular apoptosis and (B) western blot analyses of p-JNK and caspase-12 following post-treatment with IFN- $\gamma /$ TNF- $\alpha$ and overexpression of FKBP11 in HT-29 cells. Bar graphs present the quantitative analysis of apoptosis rates and the densities of p-JNK, JNK and caspase-12 proteins vs. GAPDH. Data are presented as mean \pm standard error of the mean $(n=3) . ~{ }^{~} \mathrm{P}<0.05$ vs. IFN- $\gamma / \mathrm{TNF}-\alpha$ untreated control; ${ }^{*} \mathrm{P}<0.05$ vs. IFN- $\gamma / \mathrm{TNF}-\alpha$ treated control. PI, propidium iodide; IFN- $\gamma$, interferon- $\gamma$; TNF- $\alpha$, tumor necrosis factor- $\alpha$; HA, hemagglutinin; FKBP11, FK506 binding protein 11; JNK, c-Jun N-terminal kinase; p-, phospho-.

IFN- $\gamma /$ TNF- $\alpha$-induced apoptosis via negative regulation of the JNK-caspase signaling pathway.

\section{Discussion}

Accumulating evidence has demonstrated that disrupted ER homeostasis in IECs contributes to the pathogenesis of IBD. Prolonged ER stress and impaired UPR signaling results in excessive IEC apoptosis, defects in intestinal mucosal barrier function and augmentation of the intestinal inflammatory reaction, which together promote IBD progression $(11,42,43)$. Previous bioinformatics analysis investigating IBD revealed that FKBP11, a novel UPR protein, is highly expressed exclusively in the intestinal tissues of human CD (25). Thus, the present study aimed to investigate the possible role of FKBP11 in the intestinal epithelium homeostasis of CD. In the present study, increased expression of FKBP11 protein was detected in inflamed intestinal tissues from patients with active CD and mice with TNBS-induced colitis. Using an ER stress and apoptosis cellular model in IECs in vitro, the results of the present study suggested that highly expressed FKBP11 attenuates IFN- $\gamma /$ TNF- $\alpha$-induced apoptosis via regulation of ER stress and inhibiting the detrimental JNK-caspase apoptosis signaling pathway in IECs.

FKBP11 is a member of the PPIase family, which catalyzes the folding of proline-containing polypeptides, and thus, is important for the regulation of UPR (19). Previous studies have suggested that FKBP11 is closely associated with numerous inflammatory disorders and digestive tumors. For example, a quantitative proteomics analysis revealed a close association between highly expressed FKBP11 and insulin resistance, as well as type 2 diabetes (21). The expression of FKBP11 and other ER stress genes (activating transcription factor 4 and endoplasmin) were significantly increased by treatment with palmitate in pancreatic islet $\beta$-cells (20). Thus, FKBP11 may regulate UPR in $\beta$-cells when exposed to abnormally high levels of circulating free fatty acids, and thus participate in the pathogenesis of type 2 diabetes. In addition, enhanced 
expression of FKBP11 was demonstrated in the B cell transcriptome of patients with quiescent SLE (44). Furthermore, overexpression of FKBP11 was revealed to disrupt B cell tolerance against DNA and initiate plasma cell differentiation by acting upstream of the paired box 5 master regulator gene, which may synergistically contribute to B cell gene abnormalities in SLE immunopathology $(22,44)$. In addition, progressively elevated expression of FKBP11 during the development of HCC has been previously demonstrated, which suggests that FKBP11 may represent a novel early marker for HCC (23).

In the present study, western blot analyses and immunohistochemistry assays revealed that the expression of FKBP11 is significantly enhanced in the inflamed intestinal tissues of patients with active CD compared with healthy controls. Furthermore, using a murine model of TNBS-induced colitis, which mimics human $\mathrm{CD}$, it was revealed that the expression of FKBP11 and GRP78 were significantly upregulated in IECs compared with the control group. The results of the present study supported the previous findings of a bioinformatics analysis investigating human IBD (25), and suggested that FKBP11 may be involved in CD pathogenesis. Following this, an IFN- $\gamma /$ TNF- $\alpha$ induced ER stress cell model was established to induce ER stress in human colon epithelial cell line HT-29, and it was demonstrated that FKBP11 and GRP78 protein expression levels were increased in IFN- $\gamma / \mathrm{TNF}-\alpha$ induced HT-29 cells. Furthermore, knockdown of FKBP11 using siRNA significantly enhanced the upregulation of GRP78, suggesting that FKBP11 is important for inflammation-induced ER stress in IECs. The results of the present study did not determine the exact molecular mechanisms underlying the effect of FKBP11 upregulation in $\mathrm{CD}$, however, previous studies may provide some potential suggestions. In a genetic mouse model of ER stress-induced hepatic steatosis, $F K B P 11$ gene expression was revealed to be regulated by IRE1 $\alpha$, a conserved UPR sensor in hepatocytes (24). Notably, as a major sensor of ER stress, genetic ablation of IREI $\alpha$ in IECs has been demonstrated to result in a spontaneous colitis in mice, thus suggesting that IRE1 $\alpha$ functions as an important defense molecule against IBD (16). In conclusion, it can be suggested that IRE1 $\alpha$ positively regulates FKBP11 expression in IECs under adverse inflammatory conditions, and that the IRE1 $\alpha$-FKBP11 UPR mechanism may promote proper protein folding, attenuate ER stress and regulate intestinal epithelial homeostasis.

Three UPR pathways (IRE1 $\alpha$, PERK and ATF6 $\alpha$ ) promote cell survival by reducing misfolded protein levels, however, UPR signaling also promotes apoptotic cell death if ER stress is not attenuated (1). For example, under persistent ER stress, PERK signaling induces the expression of CHOP, a key regulator of ER stress associated apoptosis (45). In addition, decreased IRE1 $\alpha$ levels have been revealed to induce IEC apoptosis via activation of the PERK-CHOP pro-apoptotic pathway, which contributes to spontaneous colitis in IRE1 $\alpha$ knockout mice (16). Furthermore, the pro-apoptotic IRE1-TNF receptor associated factor 2 (TRAF2)-JNK pathway can be activated by prolonged ER stress (46). Signal transduction between IRE1-TRAF2 and phosphorylation of JNK may be regulated in certain contexts by MAP kinase kinase kinase apoptotic signal-regulating kinase 1 and its activator kinase (46). JNK-induced apoptosis may involve pro-apoptotic
Bcl-2 family members, BAX and Bcl-2 antagonist/killer 1, which can amplify the IRE1 signal (46). Cysteine proteases (or caspases) are important mediators of apoptosis. Different from other caspase members that are activated by membraneor mitochondrial-targeted apoptotic signals, caspase-12 is localized to the ER and is activated by ER stress via disruption of ER calcium homeostasis and accumulation of excess proteins in the ER (13). Caspase-12 activity can result in selective apoptosis in response to ER stress via cleavage of pro-caspase-3 into activated caspase-3 (13). Caspase-12, a member of the cysteine protease family, serves a role in promoting apoptosis in mice, whereas caspase-12 in humans had lost its apoptotic regulatory function due to genetic mutations, and the homeotic caspase- 4 may have the same function (47). In the present study, caspase-4 was used instead of caspase-12, as human colon cancer cells HT-29 were used. Two major pro-apoptotic pathways were revealed to be associated with ER stress: The caspase-12/caspase-3 pathway and the JNK/BAX pathway, which were significantly activated in IECs following treatment with IFN- $\gamma /$ TNF- $\alpha$. Notably, the results of the present study demonstrated that FKBP11 overexpression attenuates ER stress-related pro-apoptotic signal transduction, which suppresses IFN- $\gamma / \mathrm{TNF}-\alpha$ induced apoptosis in IECs.

In conclusion, the results of the present study demonstrated that FKBP11 and GRP78 expression levels are significantly upregulated in the inflamed intestinal mucosa of CD. Furthermore, the results revealed that overexpression of FKBP11 could attenuate IFN- $\gamma / \mathrm{TNF}-\alpha$-induced cellular apoptosis in IECs. These results are compatible with the hypothesis that increased FKBP11 expression attenuates IFN- $\gamma / \mathrm{TNF}-\alpha$ induced ER stress associated with the JNK-caspase apoptotic pathway in IECs. However, further studies are required to further validate the results of the present study and to investigate the exact molecular mechanisms of FKBP11 in intestinal epithelial homeostasis and CD development.

\section{Acknowledgements}

Not applicable.

\section{Funding}

The present study was supported by the National Natural Scientific Foundation of China (grant no. 81572397), Jiangsu Province's Outstanding Medical Academic Leader program (grant no. LJ101135) and Infectious Disease Clinical Medicine Center Program of Suzhou (grant. no. SZZX201508).

\section{Availability of data and materials}

All data generated or analyzed during this study are included in this article.

\section{Authors' contributions}

$\mathrm{XW}, \mathrm{XC}, \mathrm{DZ}$ and GZ conceived and designed the study. XW, $\mathrm{XC}, \mathrm{JZ}, \mathrm{ZS}, \mathrm{XS}$ and LW performed the experiments. HW, YS and YN established and monitored the animal colitis model. XW wrote the paper. CZ and ML analyzed the cellular 
apoptosis rates and designed the chart accordingly. DZ and GZ reviewed and edited the manuscript. All authors read and approved the manuscript.

\section{Ethics approval and consent to participate}

This experiment was performed with the approval of the Ethics Committee of the Affiliated Hospital of Nantong University (permit no. 2014-L087).

\section{Patient consent for publication}

Not applicable.

\section{Competing interests}

The authors declare that they have no competing interests.

\section{References}

1. Cao SS: Endoplasmic reticulum stress and unfolded protein response in inflammatory bowel disease. Inflamm Bowel Dis 21: 636-644, 2015

2. Tawfik A, Flanagan PK and Campbell BJ: Escherichia coli-host macrophage interactions in the pathogenesis of inflammatory bowel disease. World J Gastroenterol 20: 8751-8763, 2014.

3. Cheng L, Huang MF, Mei PF, Bo WH and Deng CS: The clinical, endoscopic and pathologic features of Crohn's disease in the differentiation from intestinal tuberculosis. Zhonghua Nei Ke Za Zhi 52: 940-944, 2013 (In Chinese)

4. Galeone C, Pelucchi C, Barbera G, Citterio C, La Vecchia C and Franchi A: Crohn's disease in Italy: A critical review of the literature using different data sources. Dig Liver Dis 49: 459-466, 2017.

5. Kim ES, Chen M, Lee J, Lee CK and Kim YS: Diagnosis of inflammatory bowel disease in Asia: The results of a multinational web-based survey in the 2(nd) Asian Organization for Crohn's and Colitis (AOCC) meeting in Seoul. Intest Res 14: 224-230, 2016

6. Guo B and Li Z: Endoplasmic reticulum stress in hepatic steatosis and inflammatory bowel diseases. Front Genet 5: 242, 2014.

7. Hisamatsu T, Kanai T, Mikami Y, Yoneno K, Matsuoka K and Hibi T: Immune aspects of the pathogenesis of inflammatory bowel disease. Pharmacol Ther 137: 283-297, 2013.

8. Salim SY and Söderholm JD: Importance of disrupted intestinal barrier in inflammatory bowel diseases. Inflamm Bowel Dis 17: 362-381, 2011.

9. Cao SS: Epithelial ER stress in Crohn's disease and ulcerative colitis. Inflamm Bowel Dis 22: 984-993, 2016.

10. Kaser A, Adolph TE and Blumberg RS: The unfolded protein response and gastrointestinal disease. Semin Immunopathol 35 307-319, 2013.

11. Luo K and Cao SS: Endoplasmic reticulum stress in intestinal epithelial cell function and inflammatory bowel disease. Gastroenterol Res Pract 2015: 328791, 2015.

12. Urano F, Wang X, Bertolotti A, Zhang Y, Chung P, Harding HP and Ron D: Coupling of stress in the ER to activation of JNK protein kinases by transmembrane protein kinase IRE1. Science 287: 664-666, 2000

13. Nakagawa T, Zhu H, Morishima N, Li E, Xu J, Yankner BA and Yuan J: Caspase-12 mediates endoplasmic-reticulum-specific apoptosis and cytotoxicity by amyloid-beta. Nature 403: 98-103, 2000

14. Kaser A, Lee AH, Franke A, Glickman JN, Zeissig S, Tilg H, Nieuwenhuis EE, Higgins DE, Schreiber S, Glimcher LH and Blumberg RS: XBP1 links ER stress to intestinal inflammation and confers genetic risk for human inflammatory bowel disease. Cell 134: 743-756, 2008.

15. Li M, Zhang S, Qiu Y, He Y, Chen B, Mao R, Cui Y, Zeng Z and Chen M: Upregulation of miR-665 promotes apoptosis and colitis in inflammatory bowel disease by repressing the endoplasmic reticulum stress components XBP1 and ORMDL3. Cell Death Dis 8: e2699, 2017.
16. Zhang HS, Chen Y, Fan L, Xi QL, Wu GH, Li XX, Yuan TL, He SQ, Yu Y, Shao ML, et al: The endoplasmic reticulum stress sensor IRE1 $\alpha$ in intestinal epithelial cells is essential for protecting against colitis. J Biol Chem 290: 15327-15336, 2015.

17. Hasnain SZ, Tauro S, Das I, Tong H, Chen AC, Jeffery PL, McDonald V, Florin TH and McGuckin MA: IL-10 promotes production of intestinal mucus by suppressing protein misfolding and endoplasmic reticulum stress in goblet cells. Gastroenterology 144: 357-368.e9, 2013

18. Shkoda A, Ruiz PA, Daniel H, Kim SC, Rogler G, Sartor RB and Haller D: Interleukin-10 blocked endoplasmic reticulum stress in intestinal epithelial cells: Impact on chronic inflammation. Gastroenterology 132: 190-207, 2007.

19. Rulten SL, Kinloch RA, Tateossian H, Robinson C, Gettins L and Kay JE: The human FK506-binding proteins: Characterization of human FKBP19. Mamm Genome 17: 322-331, 2006.

20. Kim M, Lee JS, Oh JE, Nan J, Lee H, Jung HS, Chung SS and Park KS: SIRT3 overexpression attenuates palmitate-induced pancreatic $\beta$-cell dysfunction. PLoS One 10: e0124744, 2015.

21. Lu H, Yang Y, Allister EM, Wijesekara N and Wheeler MB: The identification of potential factors associated with the development of type 2 diabetes: A quantitative proteomics approach. Mol Cell Proteomics 7: 1434-1451, 2008.

22. Ruer-Laventie J, Simoni L, Schickel JN, Soley A, Duval M, Knapp AM, Marcellin L, Lamon D, Korganow AS, Martin T, et al: Overexpression of Fkbp11, a feature of lupus B cells, leads to B cell tolerance breakdown and initiates plasma cell differentiation. Immun Inflamm Dis 3: 265-279, 2015.

23. Lin IY, Yen CH, Liao YJ, Lin SE, Ma HP, Chan YJ and Chen YM: Identification of FKBP11 as a biomarker for hepatocellular carcinoma. Anticancer Res 33: 2763-2769, 2013.

24. Zhang K, Wang S, Malhotra J, Hassler JR, Back SH, Wang G, Chang L, Xu W, Miao H, Leonardi R, et al: The unfolded protein response transducer IRE1 $\alpha$ prevents ER stress-induced hepatic steatosis. EMBO J 30: 1357-1375, 2011.

25. Clark PM, Dawany N, Dampier W, Byers SW, Pestell RG and Tozeren A: Bioinformatics analysis reveals transcriptome and microRNA signatures and drug repositioning targets for IBD and other autoimmune diseases. Inflamm Bowel Dis 18: 2315-2333, 2012.

26. Ingle SB, Adgaonkar BD, Jamadar NP, Siddiqui S and Hinge CR: Crohn's disease with gastroduodenal involvement: Diagnostic approach. World J Clin Cases 3: 479-483, 2015.

27. Yu H, Liu Y, Wang Y, Peng L, Li A and Zhang Y: Clinical, endoscopic and histological differentiations between Crohn's disease and intestinal tuberculosis. Digestion 85: 202-209, 2012.

28. National Research Council (US) Institute for Laboratory Animal Research. Guide for the care and use of laboratory animals. Washington (DC), National Academies Press (US), 1996.

29. Hollenbach E, Vieth M, Roessner A, Neumann M, Malfertheiner P and Naumann M: Inhibition of RICK/nuclear factor-kappaB and p38 signaling attenuates the inflammatory response in a murine model of Crohn disease. J Biol Chem 280: 14981-14988, 2005.

30. Zhang D, Wang L, Yan L, Miao X, Gong C, Xiao M, Ni R and Tang Q: Vacuolar protein sorting 4B regulates apoptosis of intestinal epithelial cells via p38 MAPK in Crohn's disease. Exp Mol Pathol 98: 55-64, 2015.

31. Lin H, Chen R, Jiang X, Wu X, Huang X, Dong X, Yang X, Lin X, Chen X, Chen X and Huang Z: Elevated fibrinogen-like protein 2 in TNBS-induced colitis mice: Association with Th17 and regulatory T cells. Mol Med Rep 16: 3445-3454, 2017.

32. Li L, Miao X, Ni R, Miao X, Wang L, Gu X, Yan L, Tang Q and Zhang D: Epithelial-specific ETS-1 (ESE1/ELF3) regulates apoptosis of intestinal epithelial cells in ulcerative colitis via accelerating NF- $\kappa B$ activation. Immunol Res 62: 198-212, 2015.

33. Tao T, Cheng C, Ji Y, Xu G, Zhang J, Zhang L and Shen A: Numbl inhibits glioma cell migration and invasion by suppressing TRAF5-mediated NF-KB activation. Mol Biol Cell 23: 2635-2644, 2012

34. Elson CO, SartorRB, Tennyson GS and Riddell RH: Experimental models of inflammatory bowel disease. Gastroenterology 109: 1344-1367, 1995

35. Cui X, Shan X, Qian J, Ji Q, Wang L, Wang X, Li M, Ding H, Liu Q, Chen L, et al: The suppressor of cytokine signaling SOCS1 promotes apoptosis of intestinal epithelial cells via p53 signaling in Crohn's disease. Exp Mol Pathol 101: 1-11, 2016.

36. Hosomi S, Kaser A and Blumberg RS: Role of endoplasmic reticulum stress and autophagy as interlinking pathways in the pathogenesis of inflammatory bowel disease. Curr Opin Gastroenterol 31: 81-88, 2015. 
37. Zeng LX, Tao J, Liu HL, Tan SW, Yang YD, Peng XJ, Liu ZH, Jiang $\mathrm{J}$ and $\mathrm{Wu} \mathrm{B}$ : $\beta$-Arrestin 2 encourages inflammation-induced epithelial apoptosis through ER stress/PUMA in colitis. Mucosal Immunol 8: 683-695, 2015

38. Kunde DA, Chong WC, Nerurkar PV, Ahuja KD, Just J, Smith JA, Guven N and Eri RD: Bitter melon protects against ER stress in LS174T colonic epithelial cells. BMC Complement Altern Med 17: 2, 2017

39. Hao X, Yao A, Gong J, Zhu W, Li N and Li J: Berberine ameliorates pro-inflammatory cytokine-induced endoplasmic reticulum stress in human intestinal epithelial cells in vitro. Inflammation 35: 841-849, 2012.

40. Saleh M, Vaillancourt JP, Graham RK, Huyck M, Srinivasula SM, Alnemri ES, Steinberg MH, Nolan V, Baldwin CT, Hotchkiss RS, et al: Differential modulation of endotoxin responsiveness by human caspase-12 polymorphisms. Nature 429: 75-79, 2004.

41. Hitomi J,Katayama T,Eguchi Y,Kudo T, Taniguchi M,Koyama Y, Manabe T, Yamagishi S, Bando Y, Imaizumi K, et al: Involvement of caspase-4 in endoplasmic reticulum stress-induced apoptosis and Abeta-induced cell death. J Cell Biol 165: 347-356, 2004.

42. Koh SJ, Kim JW, Kim BG, Lee KL, Chun J and Kim JS: Fexofenadine regulates nuclear factor $-\kappa \mathrm{B}$ signaling and endoplasmic reticulum stress in intestinal epithelial cells and ameliorates acute and chronic colitis in mice. J Pharmacol Exp Ther 352: 455-461, 2015.
43. Das I, Png CW, Oancea I, Hasnain SZ, Lourie R, Proctor M, Eri RD, Sheng Y, Crane DI, Florin TH and McGuckin MA: Glucocorticoids alleviate intestinal ER stress by enhancing protein folding and degradation of misfolded proteins. J Exp Med 210: 1201-1216, 2013.

44. Garaud JC, Schickel JN, Blaison G, Knapp AM, Dembele D, Ruer-Laventie J, Korganow AS, Martin T, Soulas-Sprauel P and Pasquali JL: B cell signature during inactive systemic lupus is heterogeneous: Toward a biological dissection of lupus. PLoS One 6: e23900, 2011.

45. Lin JH, Li H, Yasumura D, Cohen HR, Zhang C, Panning B, Shokat KM, Lavail MM and Walter P: IRE1 signaling affects cell fate during the unfolded protein response. Science 318: 944-949, 2007.

46. Tabas I and Ron D: Integrating the mechanisms of apoptosis induced by endoplasmic reticulum stress. Nat Cell Biol 13: 184-190, 2011.

47. Song S, Lee H, Kam TI, Tai ML, Lee JY, Noh JY, Shim SM, Seo SJ, Kong YY, Nakagawa T, et al: E2-25K/Hip-2 regulates caspase-12 in ER stress-mediated Abeta neurotoxicity. J Cell Biol 182: 675-684, 2008.

This work is licensed under a Creative Commons

Attribution-NonCommercial-NoDerivatives 4.0 International (CC BY-NC-ND 4.0) License. 